\title{
Efficacy of lignocaine gel for outpatient laser treatment in inflamed eyes
}

\begin{abstract}
Purpose To evaluate the efficacy and safety of topical $2 \%$ lignocaine gel in providing analgesia during outpatient transpupillary or trans-scleral laser treatment of inflamed eyes. Methods A prospective study was carried out of consecutive eligible eyes undergoing laser treatment using $2 \%$ lignocaine gel as a topical anaesthetic and a coupling medium. At the conclusion of each procedure, patients were asked to grade a pain score $(0=$ no discomfort, $1=$ mild discomfort, 2 = mild pain,

$3=$ moderate pain, $4=$ severe pain).

Results Twenty eyes in 19 patients received laser treatment. No pain was reported in $\mathbf{9 5 \%}$ of cases treated (no discomfort in $75 \%$, mild discomfort in $20 \%$ ) and only mild pain in $5 \%$ (one patient). No adverse reactions were encountered in any of the patients. There were no complications associated with the procedures.

Conclusions Lignocaine $2 \%$ gel is safe and effective for outpatient transpupillary and trans-scleral laser treatment in inflamed eyes, providing adequate analgesia and serving as a coupling medium at the same time.
\end{abstract}

Key words Anaesthesia, Inflamed eye, Laser, Lignocaine gel, Outpatient

Transpupillary laser therapy is a common and effective form of outpatient treatment for many ocular conditions. In most cases, the procedures are performed with a coupling agent such as methylcellulose, after instillation of a topical anaesthetic solution shortly beforehand. However, in the setting of inflamed eyes, in cases where a treatment area is close to the fovea centre or in pain-sensitive patients, other additional modes of regional anaesthesia may be required, such as retrobulbar or peribulbar injections. These injections carry uncommon but important risks. Globe perforation is one of the most serious ocular complications, ${ }^{1,2}$ and is particularly dangerous in eyes of long axial lengths and staphylomas of sclera. Systemic complications include brain stem anaesthesia, respiratory arrest, seizures and even death. ${ }^{3-5}$ Other ocular complications include retrobulbar
ALVIN K.H. KWOK, ALVIN L. YOUNG, DENNIS S.C. LAM haemorrhage, optic nerve trauma and retinal vascular occlusions. ${ }^{6-8}$ Peribulbar block has been advocated to reduce the incidence of these complications, ${ }^{9,10}$ but this procedure has also been associated with globe perforation, retrobulbar haemorrhage and extraocular paresis. ${ }^{11-13}$

$2 \%$ lignocaine gel has been shown to be a simple, safe and effective anaesthetic agent in topical cataract surgery. ${ }^{14,15}$ This study was conducted to assess the suitability of topical $2 \%$ lignocaine gel in both providing analgesia and acting as a coupling agent during outpatient transpupillary or trans-scleral laser treatment of inflamed eyes.

\section{Materials and methods}

Patients listed for transpupillary or trans-scleral outpatient laser treatment were recruited prospectively over the period from March 2000 to June 2000 at the Hong Kong Eye Hospital and Queen Mary Hospital, Hong Kong. Inclusion criteria were co-operative patients with inflammation in the eye to be treated or in whom the treatment area was close to the fovea centre. Institutional ethics approval and consent from patients were obtained. Exclusion criteria include hypersensitivity to local anaesthetic agent of the amide type, a primary ocular surface problem and secondary problems such as lid malpositions with entropion, ectropion or lagophthalmos.

\section{Study procedure}

After receiving an application of $1 \mathrm{~cm}$ length of $2 \%$ lignocaine gel (2\% Xylocaine Jelly, Astra, Sweden) in the lower conjunctival fornix of the treatment eye $1 \mathrm{~min}$ before laser therapy, the patient was allowed to rest with the eyes closed. The same gel was used as a coupling medium for the transpupillary laser contact lens. The demographic details, diagnosis, procedure performed and laser settings used were recorded. At the conclusion of each treatment, the patient was asked to grade a pain score of the procedure: $0=$ no discomfort, $1=$ mild discomfort, 2 = mild pain, 3 = moderate pain, $4=$ severe pain. 
Table 1. Patient demographics and laser procedure details of the glaucoma group

\begin{tabular}{|c|c|c|c|c|c|c|c|c|}
\hline $\begin{array}{l}\text { Patient } \\
\text { no. }\end{array}$ & $\begin{array}{l}\text { Age } \\
\text { (years) }\end{array}$ & Sex & Eye & Diagnosis & Procedure & Laser settings & Remarks & $\begin{array}{l}\text { Pain } \\
\text { score }\end{array}$ \\
\hline 1 & 66 & $\mathrm{~F}$ & Left & AACG & Sequential PI & $\begin{array}{l}\text { Argon: \#97 } \times 0.1 \mathrm{~s} \times 0.2-1 \mathrm{~W} \times 50 \mu \mathrm{m} \\
\text { YAG: \#15 × } 2-4 \mathrm{~mJ}\end{array}$ & & 1 \\
\hline 2 & 62 & M & Right & AACG & Sequential PI & $\begin{array}{l}\text { Argon: } \# 90 \times 0.1 \mathrm{~s} \times 0.2-1 \mathrm{~W} \times 50 \mu \mathrm{m} \\
\text { YAG: } \# 3 \times 2 \mathrm{~mJ}\end{array}$ & & 0 \\
\hline 3 & 63 & $\mathrm{~F}$ & Left & AACG & Sequential PI & $\begin{array}{l}\text { Argon: } \# 86 \times 0.1 \mathrm{~s} \times 0.2-1 \mathrm{~W} \times 50 \mu \mathrm{m} \\
\text { YAG: } \# 10 \times 2-3.4 \mathrm{~mJ}\end{array}$ & & 1 \\
\hline 4 & 65 & $\mathrm{~F}$ & Left & AACG & Sequential PI & $\begin{array}{l}\text { Argon: \#78 × } 0.1 \mathrm{~s} \times 0.2-0.8 \mathrm{~W} \times 50 \mu \mathrm{m} \\
\text { YAG: } \# 5 \times 2-3 \mathrm{~mJ}\end{array}$ & & 0 \\
\hline 5 & 69 & $\mathrm{~F}$ & Right & AACG & PI & Argon: \#146 × $0.1 \mathrm{~s} \times 0.2-0.8 \mathrm{~W} \times 50 \mu \mathrm{m}$ & & 0 \\
\hline 6 & 79 & $\mathrm{~F}$ & Right & $\begin{array}{l}\text { Phacomorphic } \\
\text { glaucoma }\end{array}$ & Sequential PI & $\begin{array}{l}\text { Argon: \#57 } \times 0.15 \mathrm{~s} \times 0.2-1 \mathrm{~W} \times 50 \mu \mathrm{m} \\
\text { YAG: } \# 3 \times 2.3 \mathrm{~mJ}\end{array}$ & & 0 \\
\hline 7 & 68 & $\mathrm{~F}$ & Right & $\begin{array}{l}\text { Traumatic } \\
\text { glaucoma }\end{array}$ & $\begin{array}{l}\text { Transcorneal } \\
\text { cyclophoto- } \\
\text { coagulation }\end{array}$ & Argon: \#154 × $0.5 \mathrm{~s} \times 0.4-0.59 \mathrm{~W} \times 500 \mu \mathrm{m}$ & $\begin{array}{l}\text { Second } 180^{\circ} \text {; } \\
\text { previous time } \\
\text { with topical } \\
\text { oxybuprocaine, } \\
\text { moderate pain }\end{array}$ & 1 \\
\hline 8 & 78 & M & Right & $\begin{array}{l}\text { Rubeotic } \\
\text { glaucoma }\end{array}$ & TSCPC & Diode: $\# 5 \times 1.5 \mathrm{~s} \times 1.5 \mathrm{~W}$ & & 2 \\
\hline
\end{tabular}

AACG, acute angle closure glaucoma; PI, peripheral iridotomy; TSCPC, trans-scleral cyclophotocoagulation; YAG, yttrium-aluminium-garnet.

\section{Results}

Twenty eyes of 19 consecutive patients were recruited prospectively. Ten female and 9 male patients were included, with ages ranging from 10 to 79 years (mean 59.4 years). Nine right eyes and 11 left eyes were treated. Both eyes were treated in one patient. $2 \%$ lignocaine gel was suitable as a coupling medium, providing clear view for the laser procedures to be performed. No discomfort was experienced in $75 \%$ (15 eyes) of total treated eyes; mild discomfort in $20 \%$ (4 eyes, score of 1 ) and mild pain in $5 \%$ ( 1 eye, score of 2 ). No adverse reactions were encountered in any of the patients. All the procedures were completed without additional anaesthetics. The patients were divided into a glaucoma group, postoperative group and miscellaneous retinal group, respectively.
In the glaucoma group (Table 1), 6 patients received sequential or simple peripheral iridotomy for acute angle closure glaucoma or phacomorphic glaucoma, after receiving medical anti-glaucomatous treatment. The intraocular pressures immediately before laser treatment ranged from 35 to $50 \mathrm{mmHg}$ (mean $42 \mathrm{mmHg}$ ). One eye received transcorneal cyclophotocoagulation for traumatic glaucoma after ruptured globe repair involving pars plana vitrectomy, as the iris tissue was totally avulsed during the trauma. Another patient received trans-scleral diode cyclophotocoagulation for rubeotic glaucoma. No discomfort was experienced in $50 \%$ (4) of the 8 patients; mild discomfort in $38 \%$ ( 3 patients) and only mild pain in the patient receiving trans-scleral diode cyclophotocoagulation.

Table 2. Patient demographics and laser procedure details of the post-operative group

\begin{tabular}{|c|c|c|c|c|c|c|c|c|}
\hline $\begin{array}{l}\text { Patient } \\
\text { no. }\end{array}$ & $\begin{array}{l}\text { Age } \\
\text { (years) }\end{array}$ & Sex & Eye & Diagnosis & Procedure & Laser settings & Remarks & $\begin{array}{l}\text { Pain } \\
\text { score }\end{array}$ \\
\hline 1 & 66 & $\mathrm{~F}$ & Left & $\mathrm{RD}$ & $\begin{array}{l}\text { Supplementary } \\
\text { barrier }\end{array}$ & $\begin{array}{l}\text { Argon: } \# 211 \times 0.1-0.4 \mathrm{~s} \times 200 \mu \mathrm{m} \\
\times 0.2-0.28 \mathrm{~W}\end{array}$ & & 0 \\
\hline 2 & 46 & $\mathrm{M}$ & Left & $\mathrm{RD}$ & $\begin{array}{l}\text { Supplementary } \\
\text { barrier }\end{array}$ & Argon: $\# 364 \times 0.2 \mathrm{~s} \times 0.44 \mathrm{~W} \times 500 \mu \mathrm{m}$ & $\begin{array}{l}\text { Silicone } \\
\text { oil in eye }\end{array}$ & 1 \\
\hline 3 & 74 & $\mathrm{~F}$ & Right & $\mathrm{PDR}+\mathrm{VH}$ & $\begin{array}{l}\text { Supplementary } \\
\text { PRP }\end{array}$ & Argon: \#219 × $0.1 \mathrm{~s} \times 0.43 \mathrm{~W} \times 200 \mu \mathrm{m}$ & & 0 \\
\hline 4 & 37 & $\mathrm{~F}$ & Right & $\mathrm{PDR}+\mathrm{VH}$ & $\begin{array}{l}\text { Supplementary } \\
\text { PRP }\end{array}$ & Argon: $\# 179 \times 0.2 \mathrm{~s} \times 02-0.3 \mathrm{~W} \times 500 \mu \mathrm{m}$ & & 0 \\
\hline 5 & 56 & $\mathrm{M}$ & Left & $\begin{array}{l}\mathrm{PDR}+\mathrm{VH} \\
+\mathrm{CSMO}\end{array}$ & Grid & Argon: $\# 185 \times 0.1 \mathrm{~s} \times 0.18-0.3 \mathrm{~W} \times 100 \mu \mathrm{m}$ & & 0 \\
\hline 6 & 54 & $\mathrm{M}$ & Left & $\begin{array}{l}\text { PDR, VH } \\
+ \text { CSMO }\end{array}$ & Grid & Argon: \#142 × $0.1 \mathrm{~s} \times 0.35 \mathrm{~W} \times 100 \mu \mathrm{m}$ & & 0 \\
\hline 7 & 65 & $\mathrm{M}$ & Left & $\begin{array}{l}\mathrm{PDR}+\mathrm{VH} \\
+\mathrm{CSMO}\end{array}$ & $\begin{array}{l}\text { Supplementary } \\
\text { PRP } \\
\text { Grid }\end{array}$ & $\begin{array}{l}\text { Argon: \#508 } \times 0.15 \mathrm{~s} \times 0.3 \mathrm{~W} \times 200 \mu \mathrm{m} \\
\text { Argon: } \# 80 \times 0.1 \mathrm{~s} \times 0.18-0.23 \mathrm{~W} \times 100 \mu \mathrm{m}\end{array}$ & & 0 \\
\hline 8 & 42 & $\mathrm{~F}$ & Left & PCO & YAG cap. & YAG: $\# 30 \times 2 \mathrm{~mJ}$ & $\begin{array}{l}\text { Uveitic } \\
\text { cataract, } \\
\text { poor right } \\
\text { eye vision }\end{array}$ & 0 \\
\hline
\end{tabular}

$\mathrm{RD}$, retinal detachment; PDR, proliferative diabetic retinopathy; $\mathrm{VH}$, vitreous haemorrhage; PRP, panretinal photocoagulation; CSMO, clinically significant macular oedema; PCO, posterior capsule opacification; YAG cap., yttrium-aluminium-garnet capsulotomy. 
Table 3. Patient demographics and laser procedure details of the miscellaneous retinal group

\begin{tabular}{|c|c|c|c|c|c|c|c|}
\hline $\begin{array}{l}\text { Patient } \\
\text { no. }\end{array}$ & $\begin{array}{l}\text { Age } \\
\text { (years) }\end{array}$ & Sex & Eye & Diagnosis & Procedure & Laser settings & Pain score \\
\hline 1 & 10 & M & Left & Coats' disease & Focal & Argon: $\# 13 \times 0.35 \mathrm{~s} \times 0.2 \mathrm{~W} \times 500 \mu \mathrm{m}$ & 0 \\
\hline 2 & 68 & M & Right & $\begin{array}{l}\text { Retinal break in } \\
\text { panuveitis }\end{array}$ & Barrier & Argon: $\# 84 \times 0.1 \mathrm{~s} \times 0.29 \mathrm{~W} \times 500 \mu \mathrm{m}$ & 0 \\
\hline $3 \mathrm{~A}$ & 60 & $\mathrm{M}$ & Left & IPCV & Juxtafoveal focal & Argon: $\# 29 \times 0.1 \mathrm{~s} \times 0.2 \mathrm{~W} \times 200 \mu \mathrm{m}$ & 0 \\
\hline 3B & 60 & $\mathrm{M}$ & Left & IPCV & Juxtafoveal focal & Argon: $\# 38 \times 0.1 \mathrm{~s} \times 0.18 \mathrm{~W} \times 200 \mu \mathrm{m}$ & 0 \\
\hline
\end{tabular}

IPCV, idiopathic polypoidal choroidal vasculopathy.

In the post-operative group (Table 2), 8 patients received laser therapy 1-5 days after surgery. Two patients underwent supplementary barrier laser after retinal detachment surgery. Five other patients received pars plana vitrectomy for proliferative diabetic retinopathy. Two of them received supplementary panretinal photocoagulation (PRP). Another 2 underwent grid laser for clinically significant macular oedema. One patient received both PRP and grid laser. The last patient in this group received a YAG capsulotomy for posterior capsule opacification. No discomfort was experienced in all but one patient $(88 \%)$, who only had mild discomfort.

In the miscellaneous retinal group (Table 3), 1 patient aged 10 years underwent focal laser for Coats' disease.

Another patient with panuveitis received barrier laser for a retinal break, while the last patient underwent juxtafoveal focal laser for bilateral idiopathic polypoidal choroidal vasculopathy. No discomfort was experienced in any of the patients.

\section{Discussion}

In the majority of transpupillary laser procedures, a coupling agent such as methylcellulose is normally applied, after instillation of a topical anaesthetic solution shortly beforehand. Usually the procedures can be finished without much discomfort to the patients. However, in the more painful procedures or the more pain-sensitive patients, the treatment may have to be inconveniently interrupted for the instillation of additional topical anaesthetic agent. Sometimes, additional modes of regional anaesthesia may be required, such as retrobulbar or peribulbar injections. These injections are associated with rare but serious systemic and local complications, such as brain stem anaesthesia and globe perforation, respectively. ${ }^{1-13}$ To avoid the use of sharp needles and associated complications in these injections, sub-Tenon's anaesthesia in panretinal photocoagulation has been advocated. ${ }^{16}$ However, this procedure requires surgical opening of the conjunctiva and sub-Tenon's space under aseptic condition. Additionally, complications such as orbital haemorrhage and muscle paresis have been reported. ${ }^{17,18}$

Weinberger et al. ${ }^{19}$ suggested the use of topical sodium diclofenac $0.1 \%$ drops during retinal laser photocoagulation, which was performed 30-135 min after the administration of the analgesic agent in their study. The inconveniently long waiting time is probably due to the slow penetration of the drug through the cornea into the aqueous. The highest average concentration of the drug to be found in the aqueous is at $2.4 \mathrm{~h}$ after instillation. ${ }^{20}$ On the other hand, topical lignocaine gel was reported to be effective even when applied only $5 \mathrm{~min}$ before cataract surgery. ${ }^{14,15}$ Moreover, side-effects associated with topical sodium diclofenac, such as corneal problems ${ }^{21,22}$ and exacerbation of asthma, ${ }^{23}$ have been increasingly reported. The efficacy and safety of this agent in retinal laser photocoagulation has been challenged. ${ }^{24}$

In the present study, we have shown the safety and efficacy of using $2 \%$ lignocaine gel as a topical anaesthetic as well as a coupling agent for the contact lens during laser procedures in inflamed eyes. All laser treatments were completed without any corneal or other complications. No pain was experienced in $95 \%$ of the total eyes treated in our series. Only mild pain was reported in 1 patient receiving trans-scleral cyclophotocoagulation, which normally requires periocular anaesthetic injection. Another patient receiving transcorneal cyclophotocoagulation of the remaining $180^{\circ}$ reported only mild discomfort, as compared with moderate pain even with additional topical oxybuprocaine in the first $180^{\circ}$ treatment. In addition to the glaucoma patients, post-operative cases also benefited from the early pain-free laser treatment. Supplementary barrier laser in retinal detachment surgery, as well as PRP and grid laser in diabetic eyes, could have favourably affected the post-operative course. Early post-operative YAG capsulotomy after uveitic cataract operation for an only-eye patient meant a great difference in the quality of life. After we became confident in this method, we decided to apply it in other scenarios, namely retinal laser in children and juxtafoveal laser treatment, which normally requires periocular anaesthetic injection. The superb patient comfort makes the procedure feasible and safe.

During the laser treatment, many subthreshold afferent pain stimuli summate, leading to an efferent withdrawal response such as eyelid squeezing. The noxious afferent sources originate from either the anterior or posterior parts of the eye, which include the eyelid, conjunctiva, cornea, anterior uvea and choroid. The pain fibres of the anterior segment of the eye are blocked directly by contact with lignocaine gel or indirectly through diffusion of lignocaine gel into the anterior chamber. The long ciliary nerves, which 
innervate the choroid, may also be anaesthetised by the gel. The efferent pathway manifests as ciliary spasm and eyelid squeezing, which may also be influenced by lignocaine gel as it diffuses into the anterior chamber as well as infiltrating the orbicularis muscle through the conjunctiva. As a result, the pain-relieving mechanism of lignocaine gel involves blockage of both afferent and efferent routes. Although not all afferent stimuli are completely blocked, removal of some of them may shift the pivot from threshold to subthreshold summation, thus suppressing an effective noxious stimulus.

Lignocaine gel as the coupling medium also acts as a depot for slow and continuous release of the anaesthetic.

In summary, $2 \%$ lignocaine gel as a topical anaethetic as well as a coupling medium for the contact lens during laser procedure is safe and effective in inflamed eyes. It offers considerable comfort to the patient and is likely to reduce the duration of the laser procedure. This method is also simple, convenient, cheap, and has a rapid onset of action. A randomised control trial is warranted to further ascertain its usefulness compared with other modes of anaethesia. Modifications of the present study design may include pain assessment using the visual analogue score, analysis of single eyes of single patients and laser to be performed on homogeneous groups.

\section{References}

1. Grizzard WS, Kirk NM, Pavan PR, et al. Perforating ocular injuries caused by anaesthesia personnel. Ophthalmology 1991;98:1011-6.

2. Duker JS, Belmont JB, Benson WE, et al. Inadvertent globe perforation during retrobulbar and peribulbar anaesthesia. Ophthalmology 1991;98:519-26.

3. Javitt JC, Addiego R, Friedberg HL, et al. Brain stem anaesthesia after retrobulbar block. Ophthalmology 1997;94:718-24.

4. Nicoll JMV, Acharya PA, Ahlen K, et al. Central nervous system complications after 6000 retrobulbar blocks. Anesth Analg 1987;66:1298-302.

5. Meyers EF, Ramirez RC, Boniuk I. Grand mal seizures after retrobulbar block. Arch Ophthalmol 1978;96:847.

6. Feibel RM. Current concepts in retrobulbar anaesthesia. Surv Ophthalmol 1985;30:102-10.

7. Carrol FD. Optic nerve complications of cataract extraction. Trans Am Acad Ophthalmol Otolaryngol 1973;77:623-9.
8. Morgan MD, Schatz H, Vine AK, et al. Ocular complications associated with retrobulbar injections. Ophthalmology 1988;95:660-5.

9. Benedetti S, Agostini A. Peribulbar anaesthesia in vitreoretinal surgery. Retina 1994;14:277-80.

10. Nicholson AD, Singh P, Badrinath SS, et al. Peribulbar anaesthesia for primary vitreoretinal surgery. Ophthalmic Surg 1992;23:657-61.

11. Kimble JA, Morris RE, Witherspoon CD, et al. Globe perforation from peribulbar injection. Arch Ophthalmol 1987;105:749.

12. Puustjarvi T, Purhonen S. Permanent blindness following retrobulbar haemorrhage after peribulbar anaesthesia for cataract surgery. Ophthalmic Surg 1992;23:450-2.

13. Esswein MB, von Noorden GK. Paresis of a vertical rectus muscle after cataract extraction. Am J Ophthalmol 1993;116:424-30.

14. Koch PS. Efficacy of lidocaine $2 \%$ jelly as a topical agent in cataract surgery. J Cataract Refract Surg 1999;25:632-4.

15. Barequet IS, Soriano ES, Green WR, et al. Provision of anaesthesia with single application of lidocaine $2 \%$ gel. J Cataract Refract Surg 1999;25:626-31.

16. Friedberg MA, Palmer RM. A new technique of local anaesthesia for panretinal photocoagulation. Ophthalmic Surg 1991;22:619-21.

17. Olitsky SE, Juneja RG. Orbital haemorrhage after the administration of sub-Tenon's infusion anaesthesia. Ophthalmic Surg Lasers 1997;28:145-6.

18. Spierer A, Schwalb E. Superior oblique muscle paresis after sub-Tenon's anaesthesia for cataract surgery. J Cataract Refract Surg 1999;25:144-5.

19. Weinberger D, Ron $\mathrm{Y}$, Lichter $\mathrm{H}$, et al. Analgesic effect of topical sodium diclofenac $0.1 \%$ drops during retinal laser photocoagulation. Br J Ophthalmol 2000;84:135-7.

20. Ellis PP, Pfoff DS, Bloedow DC, et al. Intraocular diclofenac and flurbiprofen concentrations in human aqueous humour following topical application. J Ocular Pharmacol 1994;10:677-82.

21. Flach A. Topically applied nonsteroidal anti-inflammatory drugs and corneal problems: an interim review and comment. Ophthalmology 2000;107:1224-6.

22. Lin JC, Rapuano CJ, Laibson PR, et al. Corneal melting associated with use of topical nonsteroidal anti-inflammatory drugs after ocular surgery. Arch Ophthalmol 2000;118:1129-32.

23. Sharir M. Exacerbation of asthma by topical diclofenac. Arch Ophthalmol 1997;115:294-5.

24. Kwok AKH, Wong TH, Lam DSC. Topical analgesia during retinal laser photocoagulation. Br J Ophthalmol 2000;84:938. 